\title{
Population pharmacokinetics of phenytoin after intravenous administration of fosphenytoin sodium in pediatric patients, adult patients, and healthy volunteers
}

\author{
Jun Tanaka • Hidefumi Kasai • Kenji Shimizu • \\ Shigeki Shimasaki • Yuji Kumagai \\ Received: 25 March 2012 / Accepted: 31 July 2012 /Published online: 24 August 2012 \\ (C) The Author(s) 2012. This article is published with open access at Springerlink.com
}

\begin{abstract}
Purpose We performed a population pharmacokinetic analysis of phenytoin after intravenous administration of fosphenytoin sodium in healthy, neurosurgical, and epileptic subjects, including pediatric patients, and determined the optimal dose and infusion rate for achieving the therapeutic range.

Methods We used pooled data obtained from two phase I studies and one phase III study performed in Japan. The population pharmacokinetic analysis was performed using NONMEM software. The optimal dose and infusion rate were determined using simulation results obtained using the final model. The therapeutic range for total plasma phenytoin concentration is $10-20 \mu \mathrm{g} / \mathrm{mL}$.

Results We used a linear two-compartment model with conversion of fosphenytoin to phenytoin. Pharmacokinetic parameters of phenytoin, such as total clearance and central and peripheral volume of distribution were influenced by body weight. The dose simulations are as follows. In adult patients, the optimal dose and infusion rate of phenytoin for achieving the therapeutic range was $22.5 \mathrm{mg} / \mathrm{kg}$ and $3 \mathrm{mg} /$ $\mathrm{kg} / \mathrm{min}$ respectively. In pediatric patients, the total plasma concentration of phenytoin was within the therapeutic range for a shorter duration than that in adult patients at $22.5 \mathrm{mg} /$ $\mathrm{kg}(3 \mathrm{mg} / \mathrm{kg} / \mathrm{min})$. However, many pediatric patients
\end{abstract}

J. Tanaka $(\bowtie) \cdot$ H. Kasai

Clinical Study Management Division, Bell Medical Solutions Inc.,

Tokyu Bldg. East NO. 3, 2-16-8, Minami-Ikebukuro, Toshimaku,

Tokyo 171-0022, Japan

e-mail: tanaka.jun@bell-medical.co.jp

K. Shimizu $\cdot$ S. Shimasaki

Division of Research and Development, Nobelpharma Co. Ltd.,

Tokyo, Japan

Y. Kumagai

Clinical Trial Center, Kitasato University East Hospital,

Kanagawa, Japan showed phenytoin concentration within the toxic range after administration of a dose of $30 \mathrm{mg} / \mathrm{kg}$.

Conclusions The pharmacokinetics of phenytoin after intravenous administration of fosphenytoin sodium could be described using a linear two-compartment model. The administration of fosphenytoin sodium $22.5 \mathrm{mg} / \mathrm{kg}$ at an infusion rate of $3 \mathrm{mg} / \mathrm{kg} / \mathrm{min}$ was optimal for achieving the desired plasma phenytoin concentration.

Keywords Fosphenytoin sodium injection · Phenytoin · Status epilepticus · Epileptic seizure $\cdot$ Population pharmacokinetics

\section{Introduction}

Fosphenytoin sodium was developed as a phenytoin prodrug to improve the low solubility of phenytoin sodium injection, which is used for the treatment of seizures, such as those in status epilepticus. Fosphenytoin sodium was approved in the United States in 1996 and subsequently in many other countries. Because the demand for fosphenytoin in Japan increased immediately after its approval in other countries, clinical trials were performed, and the drug was approved in July 2011.

Many studies have reported the population pharmacokinetics of phenytoin [1-3], but almost all studies have been performed at the steady-state trough levels of phenytoin. Ahn et al. [4] analyzed the population pharmacokinetics of phenytoin after fosphenytoin administration using plasma concentration data, including data from samples taken shortly after administration, but pediatric patients were not included in this study. We examined the population pharmacokinetics of phenytoin after intravenous administration of fosphenytoin sodium on the basis of data obtained from two phase I studies in healthy adult volunteers and one phase III study in pediatric and adult patients. Further, we 
established the optimal dose and rates of fosphenytoin sodium injection in Japan on the basis of these results.

\section{Materials and methods}

\section{Study design}

We conducted a population pharmacokinetic analysis of phenytoin by using pooled data obtained from two phase I studies and one phase III study. In addition, the data of phenytoin administration in phase I study was used in the population analysis.

In one of the phase I studies, 12 healthy adult volunteers participated in a single-dose, randomized, double-blind, two-period crossover study. Phenytoin sodium $250 \mathrm{mg}$ and fosphenytoin sodium $375 \mathrm{mg}$ were intravenously administered at infusion rates of $8.3 \mathrm{mg} / \mathrm{min}$ (administration time, $30 \mathrm{~min}$ ) and $12.5 \mathrm{mg} / \mathrm{min}(30 \mathrm{~min})$ respectively. The washout period between the two treatments was set at a minimum of two weeks.

In the second phase I study, 12 healthy adult volunteers participated in a single-dose, randomized, open-label, twoperiod, dose-escalation study. They were randomly allocated to one of two groups. Each group was intravenously administered a single dose of fosphenytoin sodium $563 \mathrm{mg}$ at a rate of $18.8 \mathrm{mg} / \mathrm{min}(30 \mathrm{~min})$ or $56.3 \mathrm{mg} / \mathrm{min}(10 \mathrm{~min})$. After a two-week of washout period, fosphenytoin sodium $750 \mathrm{mg}$ was intravenously administered at a rate of $25 \mathrm{mg} /$ $\min (30 \mathrm{~min})$ or $75 \mathrm{mg} / \mathrm{min}(10 \mathrm{~min})$.

In phase I studies, 16 blood samples were collected from each subject before dosing, and at 10,20,30, 40, and $50 \mathrm{~min}$, and 1, 1.25, 1.5, 2, 4, 8, 12, 24, 48, and $72 \mathrm{~h}$ after the start of drug administration.

In the phase III study, neurosurgical patients were intravenously administered fosphenytoin sodium 15 or $18 \mathrm{mg} / \mathrm{kg}$ at an infusion rate of $1 \mathrm{mg} / \mathrm{kg} / \mathrm{min}$ (15 or $18 \mathrm{~min}$ ) for the prevention of seizure after brain surgery or head trauma in an open-label manner. The epileptic patients, including those with status epilepticus and acute repetitive seizures, were intravenously administered fosphenytoin sodium 18 or $22.5 \mathrm{mg} / \mathrm{kg}$ at an infusion rate of $3 \mathrm{mg} / \mathrm{kg} / \mathrm{min}$ ( 6 or $7.5 \mathrm{~min}$ for patients weighing $<50 \mathrm{~kg}$ ). The maximum infusion rate did not exceed $150 \mathrm{mg} / \mathrm{min}$ for any patient. Seven blood samples were collected from each patient before dosing and at 10 and $20 \mathrm{~min}$, and 1, 2, 4, and $24 \mathrm{~h}$ after administration of drugs.

All studies were performed in accordance with the ICH Guidelines for Good Clinical Practice. The study protocols were reviewed and approved by the Institutional Review Boards of each clinical study site. Written informed consent was obtained from subjects or legally authorized representatives before participation in the study.
Assay of total plasma phenytoin concentrations

Plasma samples were collected at each sampling point and were immediately frozen and stored at or below $-20^{\circ} \mathrm{C}$ until analysis. Plasma samples from all studies were assayed at the time of each study in the Analysis Center (Sumika Chemical Analysis Service, Ltd., Osaka, Japan). Phenytoin was extracted from $20-\mu \mathrm{L}$ plasma samples using diethyl ether under acidic conditions, and the phenytoin concentration was determined using liquid chromatography coupled with tandem mass spectrometry (LC/MS/MS). Dexamethasone sodium phosphate and mephenytoin were used as the internal standard. The linear range was obtained between 0.1 and $50 \mu \mathrm{g} / \mathrm{mL}$ ( $\mathrm{r} \geq 0.9976$ ). Performance characteristics for LC/MS/MS assay are presented in Table 1. The quantitation method was validated for accuracy, precision, sensitivity, and specificity.

Population pharmacokinetic modeling

\section{Software and algorithms}

The population pharmacokinetic analysis of phenytoin was performed using the non-linear mixed effect model (NONMEM) software package, version VI level 2.0 [5]. The first order conditional estimation with interaction algorithm was used for parameter estimation. Conditional weighted residual (CWRES) was calculated based on the literature of Hooker et al. [6] using the R software [7]. Bootstrap resampling [8] was performed using the MULTTEST procedure of SAS software (SAS Institute Inc.).

\section{Structural model}

A linear two-compartment model with conversion of fosphenytoin to phenytoin (Fig. 1) was employed for the population pharmacokinetic analysis of phenytoin, because the maximum concentration $\left(\mathrm{C}_{\max }\right)$ of phenytoin indicated dose proportionality in the phase I study. The basic pharmacokinetic parameters were total clearance $(\mathrm{CL}, \mathrm{L} / \mathrm{h})$; central volume of distribution $\left(\mathrm{V}_{2}, \mathrm{~L}\right)$; inter-compartmental clearance $(\mathrm{Q}, \mathrm{L} / \mathrm{h})$; peripheral volume of distribution $\left(\mathrm{V}_{3}, \mathrm{~L}\right)$; and metabolism rate constant $\left(\mathrm{K}_{12}, \mathrm{~h}^{-1}\right)$. The bioavailability of

Table 1 Performance characteristics for liquid chromatography coupled with tandem mass spectrometry assay

\begin{tabular}{lc}
\hline Internal standard & $\begin{array}{l}\text { Total phenytoin } \\
\text { Mephenytoin }\end{array}$ \\
\hline Linearity $(\mu \mathrm{g} / \mathrm{mL})$ & $0.1-50 \mu \mathrm{g} / \mathrm{mL}(\mathrm{r} \geq 0.9974)$ \\
Interassay precision (\%RSD) & $3.6-6.4$ \\
Interassay accuracy (\% relative error) & -10.1 to -3.4 \\
\hline
\end{tabular}




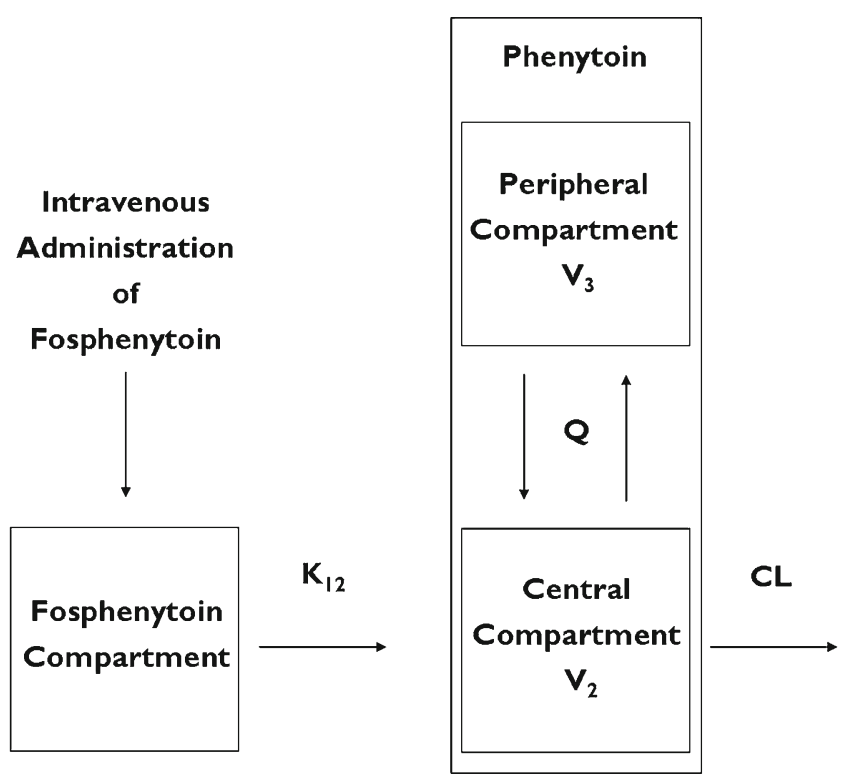

Fig. 1 Structure of the two-compartment model with conversion of fosphenytoin to phenytoin

phenytoin derived from intravenous fosphenytoin sodium injection is approximately 1 [9].

The inter-individual variability was investigated for all pharmacokinetic parameters. The inter-individual variability was calculated using an exponential error model as follows:

$\theta_{\mathrm{i}}=\theta \times \exp \left(\eta_{\mathrm{i}}\right)$

where $\theta_{i}$, is the $i^{\text {th }}$ individual estimate of the parameter; $\theta$, the typical population estimate; and $\eta_{i}$, the normally distributed inter-individual random effect of mean 0 and variance $\omega^{2}$.

The residual variability was determined by using an exponential error model or combined exponential and additive error model as follows:

$\mathrm{Y}_{\mathrm{ij}}=\mathrm{F}_{\mathrm{ij}} \times \exp \left(\varepsilon_{1 \mathrm{ij}}\right)$

$\mathrm{Y}_{\mathrm{ij}}=\mathrm{F}_{\mathrm{ij}} \times \exp \left(\varepsilon_{1 \mathrm{ij}}\right)+\varepsilon_{2 \mathrm{ij}}$,

where $Y_{i j}$ and $F_{i j}$ represent the $j^{\text {th }}$ observed or predicted concentration for the $i^{\text {th }}$ subject respectively, and $\varepsilon_{1 \mathrm{ij}}$ and $\varepsilon_{2 \mathrm{ij}}$ are the residual random effect of mean 0 and variance $\sigma_{1}^{2}$ and $\sigma_{2}^{2}$ respectively. The model judged to be the best structural model on the basis of the goodness-of-fit plots, $95 \%$ confidence interval of the parameter estimate, and the likelihood ratio test was chosen as the base model.

\section{Covariate evaluation}

Several covariates that could influence the pharmacokinetics of phenytoin were added one by one to the base model. The model that incorporated all possible covariates was chosen as the full model (forward step).
The effects of body weight (BW), age, gender, and trial patient type on each pharmacokinetic parameter were examined. For BW and age, a covariate model was developed using the power function model as follows:

$\theta=\theta_{1} \times\left(\mathrm{COV} / \mathrm{COV}_{\text {typical value }}\right)^{\theta \mathrm{COV}}$,

where $\theta \mathrm{COV}$ is the influence factor to be estimated; $\theta_{1}$ the value of the pharmacokinetic parameter for subject with typical value of covariate; and $\theta$, the typical value of the pharmacokinetic parameter.

Gender and trial patient type were modeled as follows:

$\theta=\theta_{1} \times\left(\theta_{\text {cov }}\right)^{\text {cov }}$,

where the variable cov was assigned a value of 0 for men or non-applicable subjects and 1 for women or applicable subjects and $\theta_{\text {cov }}$ was a covariate difference in $\theta$.

After the forward step, each covariate in the full model was tested in turn by removing each entity one by one to confirm the statistical significance. The model with only significant covariates was chosen as the final model (backward elimination step).

\section{Model evaluation}

The population pharmacokinetic model was evaluated on the basis of goodness-of-fit plots, $95 \%$ confidence interval for the parameter estimates, and the likelihood ratio test. The $95 \%$ confidence interval for parameter estimates was obtained from the point estimate $\pm 1.96 \times$ standard error $(\mathrm{SE})$, which was taken from the covariance step. The coefficient of variance (CV [\%]) for individual variability and intra-individual variability were calculated from the square root of the variance. In the likelihood ratio test, the objective function value difference $(\triangle \mathrm{OBJ})$ was used for evaluating the statistical significance of the parameters. The $p$ values for the forward selection step and backward elimination step were $<0.05$ ( $\triangle \mathrm{OBJ}$ was $<3.84$ ) and $P<0.01$ ( $\triangle \mathrm{OBJ}$ was $>6.63$ ) respectively.

Bootstrap validation was used to evaluate the validity and robustness of the final model. Two hundred data sets were reconstructed by resampling the subjects from the original data set. Successful estimation was defined as the normal completion of both the estimation and covariance steps of the NONMEM software. The mean parameter estimates and standard error obtained from the bootstrap replications were compared with the final parameter estimates and standard error obtained from the original data set. The model for which the probability of a successful bootstrap run was more than $90 \%$ and the parameter estimates were comparable was defined as the robust model.

\section{Simulation}

The optimal dose and infusion rate were examined on the basis of the results of the simulation. The simulations of 

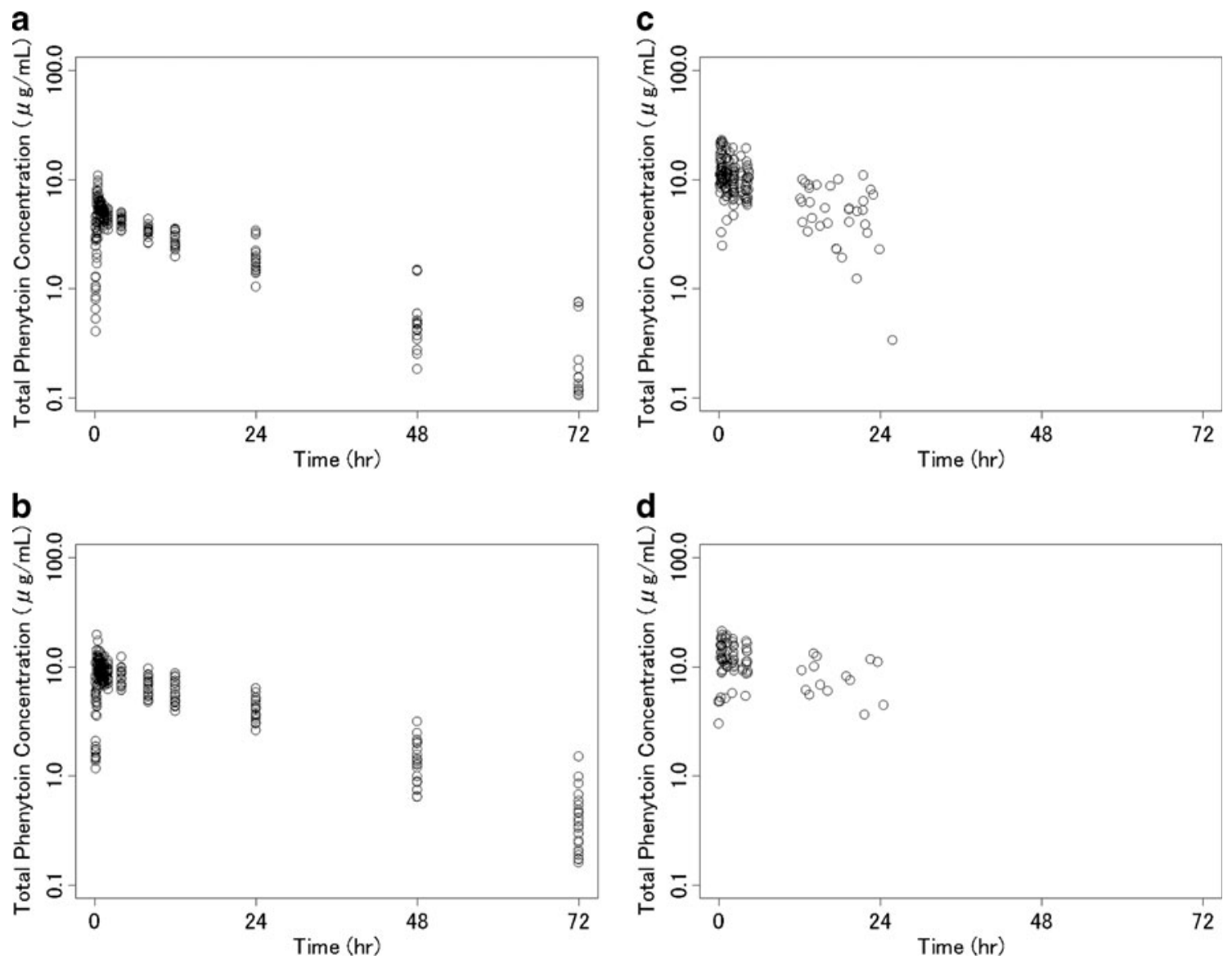

Fig. 2 Total plasma phenytoin concentrations obtained from clinical studies. a Healthy volunteers $(n=12)$ in a Phase I study (study in which phenytoin sodium and fosphenytoin sodium were administered).

pediatric and adult patients using the final population model were produced using data sets of 200 subjects depending on the following doses and rates. The doses and rates used for patients in the study and the maximum dose in the United States $(30 \mathrm{mg} / \mathrm{kg})$ were selected. The data sets for pediatric and adult patients were reconstructed by resampling the values from the covariate data observed in the phase III study. The simulations were performed to check for profiles that remained within the therapeutic range and those that crossed the toxicity threshold:

1. Dose of $15 \mathrm{mg} / \mathrm{kg}$ body weight (rate: $1 \mathrm{mg} / \mathrm{kg} / \mathrm{min}$ )

2. Dose of $18 \mathrm{mg} / \mathrm{kg}$ body weight (rate: $1 \mathrm{mg} / \mathrm{kg} / \mathrm{min}$ )

b Healthy volunteers $(n=12)$ in a Phase I study (dose-escalation study). c Pediatric patients $(n=33)$ in a Phase III study. d Adult patients $(n=14)$ in a Phase III study

3. Dose of $18 \mathrm{mg} / \mathrm{kg}$ body weight (rate: $3 \mathrm{mg} / \mathrm{kg} / \mathrm{min}$ )

4. Dose of $22.5 \mathrm{mg} / \mathrm{kg}$ body weight (rate: $3 \mathrm{mg} / \mathrm{kg} / \mathrm{min}$ )

5. Dose of $30 \mathrm{mg} / \mathrm{kg}$ body weight (rate: $3 \mathrm{mg} / \mathrm{kg} / \mathrm{min}$ )

\section{Results}

The population pharmacokinetic analysis was performed using data 923 plasma concentrations collected from 24 healthy volunteers, 14 adult patients, and 33 pediatric patients. The plot of time versus total plasma phenytoin concentration is shown in Fig. 2. Descriptive statistics are presented in Table 2.

Table 2 Summary of patients used in the evaluation

\begin{tabular}{lcccc}
\hline Demographic & All patients & Phase I study patients & $\begin{array}{c}\text { Phase III study patients } \\
\text { (adult patients [ } \geq 17])\end{array}$ & $\begin{array}{l}\text { Phase III study patients } \\
\text { (pediatric patients [2-16]) }\end{array}$ \\
\hline Gender (man/woman) & $44 / 27$ & $24 / 0$ & $7 / 7$ & $13 / 20$ \\
Age (years) & $19.6 \pm 15.6(2-86)$ & $24.9 \pm 5.1(20-37)$ & $38.2 \pm 21.1(17-86)$ & $7.8 \pm 4.3(2-16)$ \\
Body weight $(\mathrm{kg})^{\mathrm{a}}$ & $43.8 \pm 21.3(7.8-74.4)$ & $64.8 \pm 5.1(56.9-74.4)$ & $53.5 \pm 9.9(39.0-72.2)$ & $24.4 \pm 13.0(7.8-60.3)$ \\
\hline
\end{tabular}

${ }^{a}$ Arithmetic mean \pm standard deviation (minimum to maximum) 
Table 3 Parameter estimates from the final population pharmacokinetic model and results of the bootstrap analysis

\begin{tabular}{|c|c|c|c|c|c|c|c|}
\hline Parameter & & Estimate & Standard error & $95 \% \mathrm{CI}$ & Bootstrap estimate & Bootstrap standard error & Bootstrap 95\% CI \\
\hline \multicolumn{8}{|l|}{ Population mean } \\
\hline $\mathrm{CL}(\mathrm{L} / \mathrm{h})^{\mathrm{a}}$ & $\theta_{1}$ & 1.61 & 0.0933 & $1.43-1.79$ & 1.61 & 0.0878 & $1.48-1.74$ \\
\hline$\Theta_{\mathrm{WT}}^{(\mathrm{CL})}$ & $\theta_{2}$ & 0.569 & 0.0862 & $0.400-0.738$ & 0.575 & 0.0912 & $0.431-0.734$ \\
\hline $\mathrm{V}_{2}(\mathrm{~L})^{\mathrm{a}}$ & $\theta_{3}$ & 20.8 & 1.99 & $16.9-24.7$ & 20.3 & 2.68 & $16.1-25.0$ \\
\hline $\mathrm{Q}(\mathrm{L} / \mathrm{h})$ & $\theta_{4}$ & 53.0 & 4.75 & $43.7-62.3$ & 53.4 & 5.87 & $44.9-64.1$ \\
\hline $\mathrm{V}_{3}(\mathrm{~L})^{\mathrm{a}}$ & $\theta_{5}$ & 26.0 & 1.55 & $23.0-29.0$ & 26.5 & 2.43 & $22.8-30.7$ \\
\hline$\Theta_{\mathrm{WT}}{ }^{(\mathrm{V} 3)}$ & $\theta_{6}$ & 0.584 & 0.0434 & $0.499-0.669$ & 0.591 & 0.0520 & $0.495-0.674$ \\
\hline $\mathrm{K}_{12}(1 / \mathrm{h})$ & $\theta_{7}$ & 5.02 & 0.399 & $4.24-5.80$ & 4.96 & 0.518 & $4.21-6.00$ \\
\hline \multicolumn{8}{|l|}{ Inter-subject variability } \\
\hline$\omega_{\mathrm{CL}, \mathrm{CL}}$ & $\omega_{1,1}$ & 0.194 & 0.0391 & $0.117-0.271$ & 0.190 & 0.0348 & $0.135-0.252$ \\
\hline$\omega_{\mathrm{V} 2, \mathrm{~V} 2}$ & $\omega_{2,2}$ & 0.161 & 0.0576 & $0.0481-0.274$ & 0.133 & 0.0684 & $0.0164-0.236$ \\
\hline$\omega_{\mathrm{Q}, \mathrm{Q}}$ & $\omega_{3,3}$ & 0.271 & 0.0840 & $0.106-0.436$ & 0.289 & 0.119 & $0.121-0.494$ \\
\hline$\omega_{\mathrm{V} 3, \mathrm{~V} 3}$ & $\omega_{4,4}$ & 0.0430 & 0.0167 & $0.0103-0.0757$ & 0.0470 & 0.0214 & $0.0179-0.0900$ \\
\hline$\omega_{\mathrm{K} 12, \mathrm{~K} 12}$ & $\omega_{5,5}$ & 0.106 & 0.0483 & $0.0110-0.201$ & 0.112 & 0.0565 & $0.0377-0.209$ \\
\hline \multicolumn{8}{|c|}{ Intra-individual variability } \\
\hline$\sigma^{2}$ (exponential error) & $\sigma_{1,1}$ & 0.00148 & 0.000692 & $0.000124-0.00284$ & 0.00181 & 0.00110 & $0.000495-0.00343$ \\
\hline$\sigma^{2}$ (additive error) & $\sigma_{2,2}$ & 0.317 & 0.0977 & $0.126-0.508$ & 0.304 & 0.100 & $0.159-0.473$ \\
\hline
\end{tabular}

${ }^{\mathrm{a}} \mathrm{CL}, \mathrm{V} 2$, and V3 are typical values for an individual weighing $60 \mathrm{~kg}$

The pharmacokinetics of phenytoin was well-described using the two-compartment model with conversion of fosphenytoin to phenytoin, which included the inter-individual variability of all pharmacokinetic parameters. Residual variability was modeled using a combined error. In the forward selection, $\mathrm{CL}, \mathrm{V}_{2}$, and $\mathrm{V}_{3}$ were influenced by $\mathrm{BW}$. In addition,
Fig. 3 Goodness-of-fit plots for the final population pharmacokinetic model for fosphenytoin. a The population-predicted concentrations versus the observed concentrations. b The individual predicted concentrations versus the observed concentrations. $\mathbf{c}$ The population-predicted concentrations versus the individual conditional weighted residuals. d Time versus the individual conditional weighted residuals
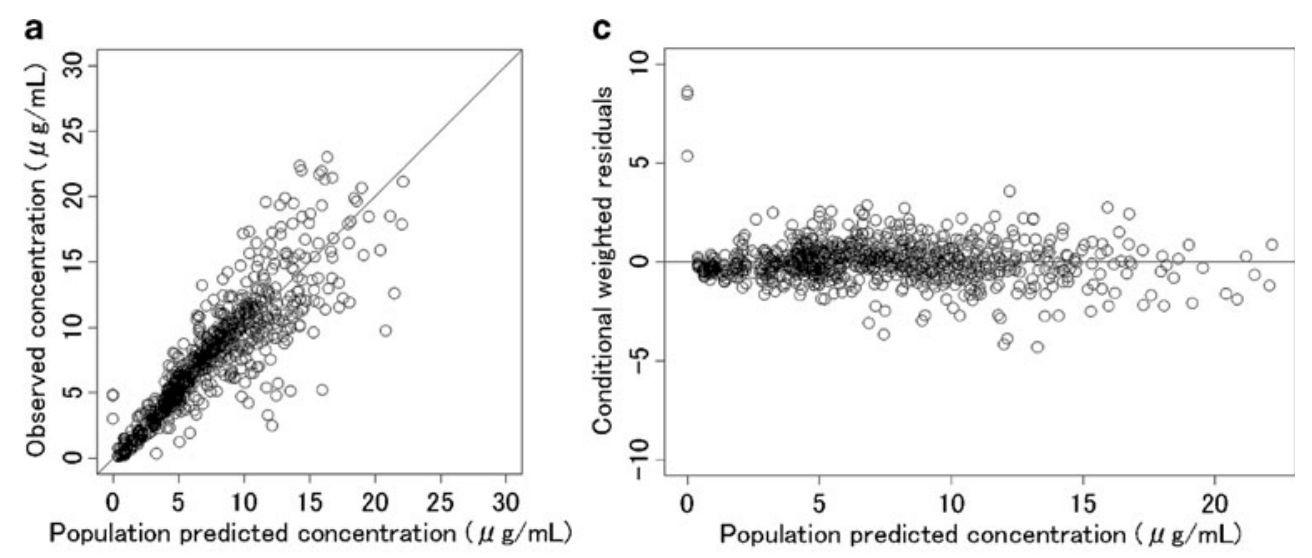

b

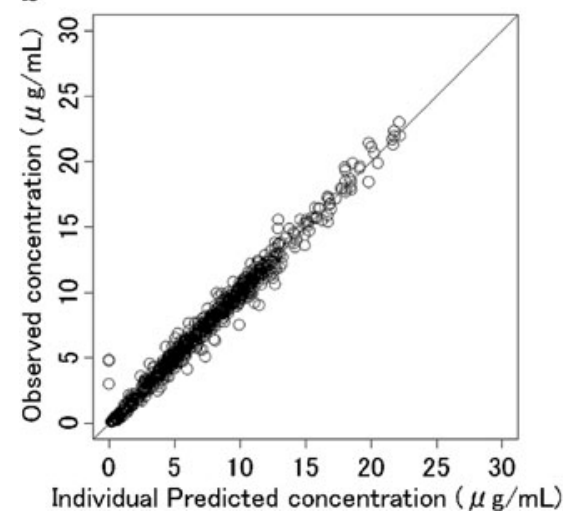

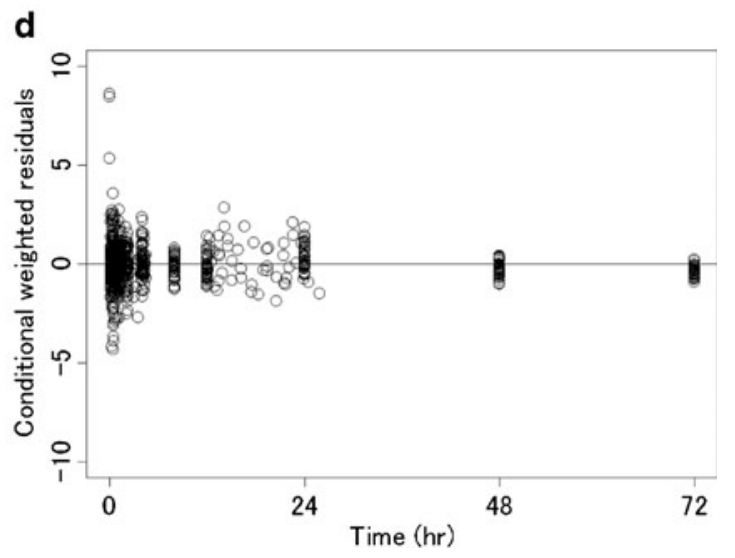


$\mathrm{V}_{3}$ was influenced by age and gender, but the influence of these parameters was not statistically significant. Therefore, $\mathrm{V}_{3}$ was related only to BW. The average BW of adult Japanese men $(60 \mathrm{~kg})$ was selected as the standard value. In the backward elimination, no covariate was eliminated from the full model. The influence factor of $\mathrm{V}_{2}$ was fixed to 1 on the basis of statistical significance $(P<0.01)$. The final model and its parameter estimates are shown in Table 3 and Eq. 1.

$$
\begin{aligned}
& \mathrm{CL}=\theta_{\mathrm{CL}} *(\mathrm{WT} / 60)^{\theta \mathrm{wt}(\mathrm{CL})} * \mathrm{e}^{\eta \mathrm{CL}} \\
& \mathrm{V}_{2}=\theta_{\mathrm{V} 2} *(\mathrm{WT} / 60) * \mathrm{e}^{\eta \mathrm{V} 2} \\
& \mathrm{Q}=\theta_{\mathrm{Q}} * \mathrm{e}^{\eta \mathrm{Q}} \\
& \mathrm{V}_{3}=\theta_{V 3} *(\mathrm{WT} / 60)^{\theta \mathrm{wt}(\mathrm{V} 3)} * \mathrm{e}^{\eta \mathrm{V} 3} \\
& \mathrm{~K}_{12}=\theta_{\mathrm{K} 12} * \mathrm{e}^{\eta \mathrm{K} 12}
\end{aligned}
$$

The goodness-of-fit plots of the final model are shown in Fig. 3. The concentrations predicted using the model and the individual predicted concentrations were consistent with the observed concentrations. The plots for time and the model predicted concentration versus CWRES presented good distribution around 0 .

The results of the bootstrap validation are shown in Table 3. The success rate was $91.0 \%$, and the estimated population values and the average of the bootstrap results were fairly consistent, which suggested good stability in parameter estimates.

The individual pharmacokinetic parameters of the subjects based on the final model are shown in Fig. 4.

The dose simulation for determining the optimal dose and rate of infusion for pediatric patients and adult patients are as follows (Fig. 5): in adult patients, the $\mathrm{C}_{\max }$ of total plasma phenytoin was within the therapeutic range $(10-20 \mu \mathrm{g} / \mathrm{mL})$ at doses of $18 \mathrm{mg} / \mathrm{kg}$ (rates of 1 and $3 \mathrm{mg} / \mathrm{kg} / \mathrm{min}$ ) or less, but the drug concentration did not remain over $10 \mu \mathrm{g} / \mathrm{mL}$ for a long
Fig. 4 The individual pharmacokinetic parameters of the subjects based on the final model. Triangle, pediatric patients $(n=33)$; cross, adult patients $(n=14)$; circle, healthy volunteers $(n=24)$
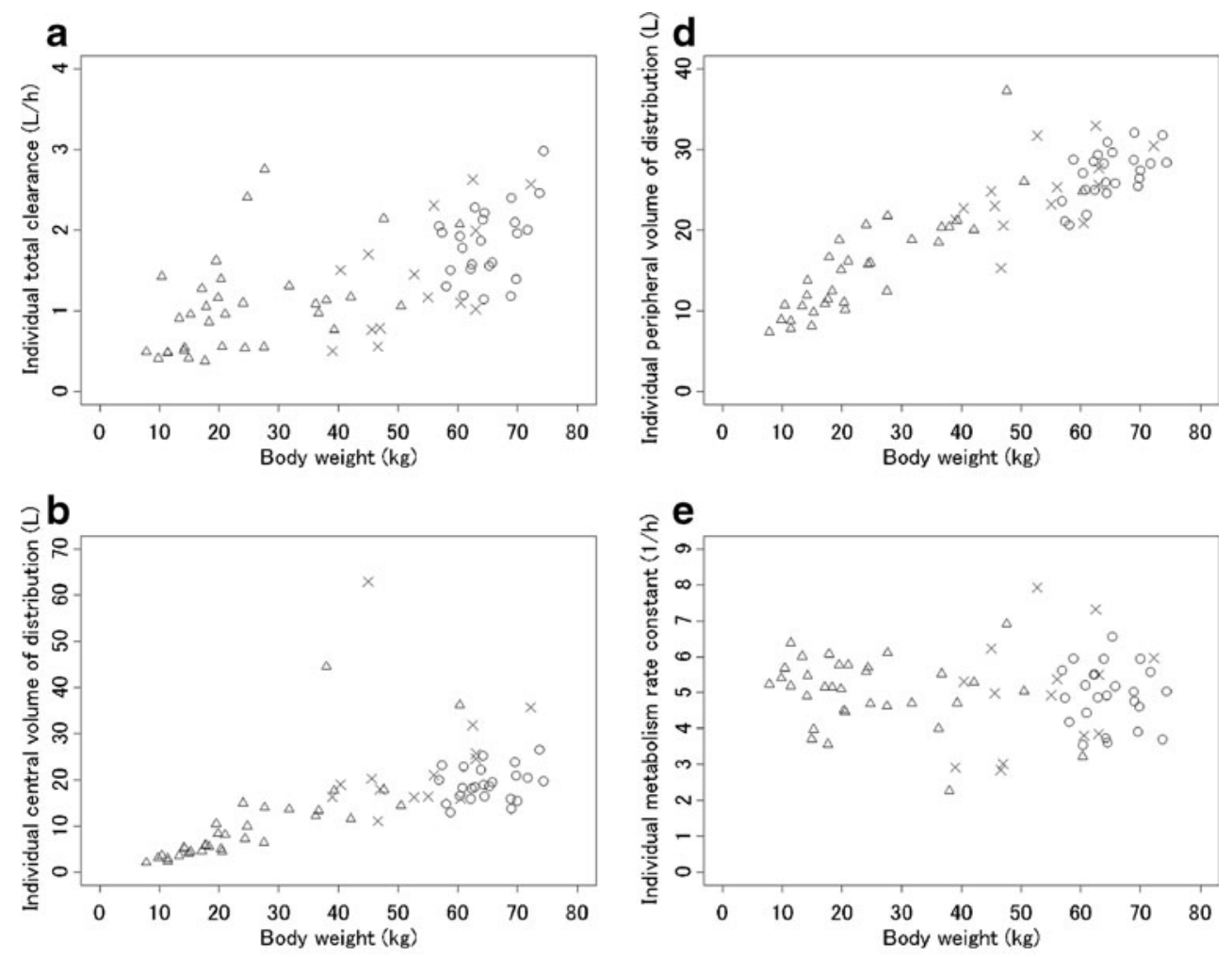
duration. The appropriate profile for retaining the therapeutic range was shown at a dose of $22.5 \mathrm{mg} / \mathrm{kg}$ with a rate of $3 \mathrm{mg} /$ $\mathrm{kg} / \mathrm{min}$. On the other hand, $\mathrm{C}_{\max }$ values were more than $20 \mu \mathrm{g} /$ $\mathrm{mL}$ in almost all simulations at a dose of $30 \mathrm{mg} / \mathrm{kg}$. In pediatric patients, the total plasma phenytoin concentration remained within the therapeutic range from 10 to $20 \mu \mathrm{g} / \mathrm{mL}$ for a short duration at a dose of $18 \mathrm{mg} / \mathrm{kg}$ or less. The concentration ranged from 10 to $20 \mu \mathrm{g} / \mathrm{mL}$ for shorter duration in pediatric patients than in adult patients at $22.5 \mathrm{mg} / \mathrm{kg}$ (a rate of $3 \mathrm{mg} / \mathrm{kg} / \mathrm{min}$ ).
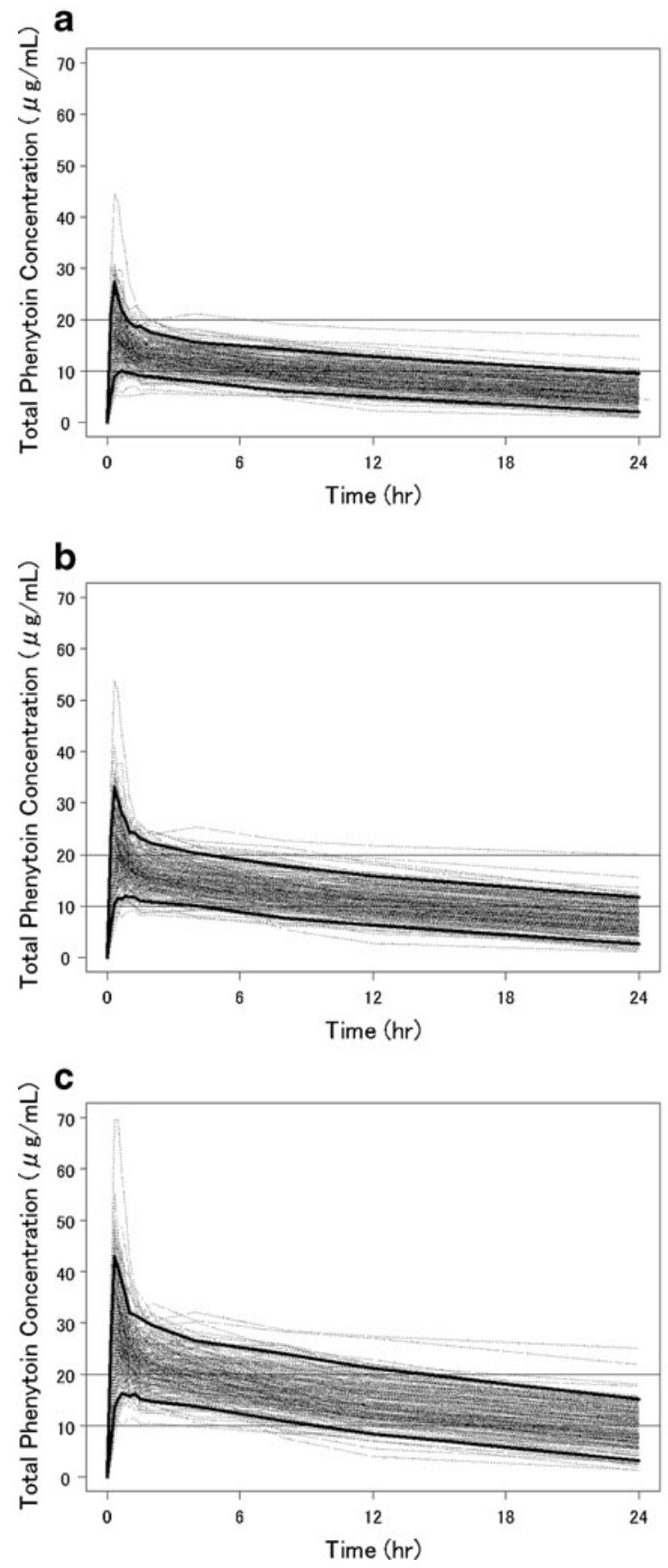

Fig. 5 The simulated total plasma phenytoin concentrations. a Adults, dose: $18 \mathrm{mg} / \mathrm{kg}$. b Adults, dose: $22.5 \mathrm{mg} / \mathrm{kg}$. c Adults, dose: $30 \mathrm{mg} / \mathrm{kg}$. d Children, dose: $18 \mathrm{mg} / \mathrm{kg}$. e Children, dose: $22.5 \mathrm{mg} / \mathrm{kg}$. f Children,
Many pediatric patients showed phenytoin concentration in the toxic range when administered at a dose of $30 \mathrm{mg} / \mathrm{kg}$.

\section{Discussion}

Although our study was a retrospective population pharmacokinetic analysis, all the data obtained from the studies conducted in Japan were used.
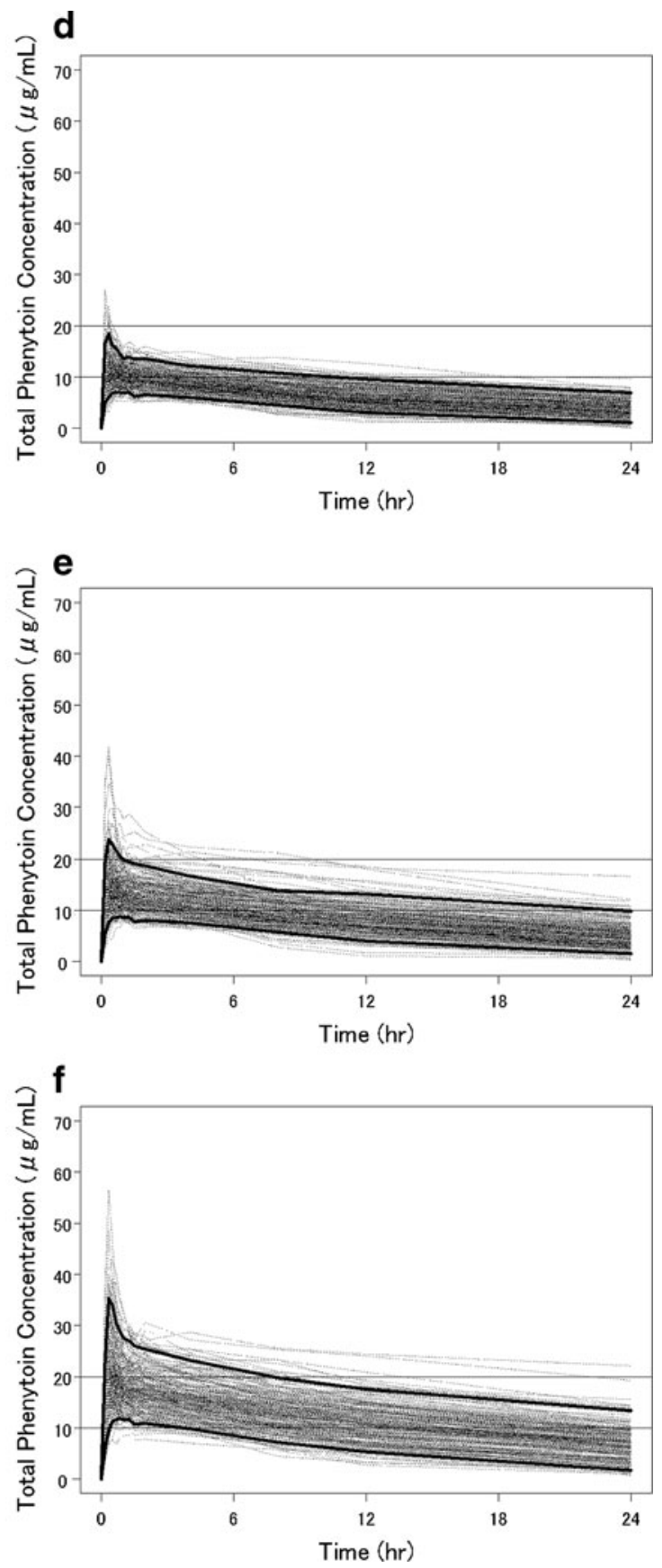

dose: $30 \mathrm{mg} / \mathrm{kg}$; rate, $3 \mathrm{mg} / \mathrm{kg} / \mathrm{min}$ ). Dotted line, individual simulated concentrations using the final model; solid line, 95 percentile or 5 percentile of predicted values using the final model 
Phenytoin metabolism can be saturated if sufficiently high doses are administered [10], but the $C_{\max }$ values showed the dose proportionality in this dose escalation study. Therefore, the saturation of the metabolism of phenytoin was not a problem in this study, and the pharmacokinetics of phenytoin after intravenous administration of fosphenytoin sodium was described using a linear twocompartment model.

The residual plots of data obtained using Odani's and Ahn's population pharmacokinetic models are shown in Fig. $6[1,4]$. Odani's model was a one-compartment model with Michaelis-Menten (MM) elimination. Maximal elimination rate $\left(\mathrm{V}_{\max }\right)$ and volume of distribution $(\mathrm{Vd})$ were adjusted for hypothetical body size. Ahn used a linear onecompartment model with drug depot compartment for fosphenytoin. CL and Vd were adjusted for body weight. Plots for time versus CWRES reflected a bias from 0 to $24 \mathrm{~h}$ in both the models. Neither of the one-compartment models could predict the total plasma phenytoin concentrations in the distribution
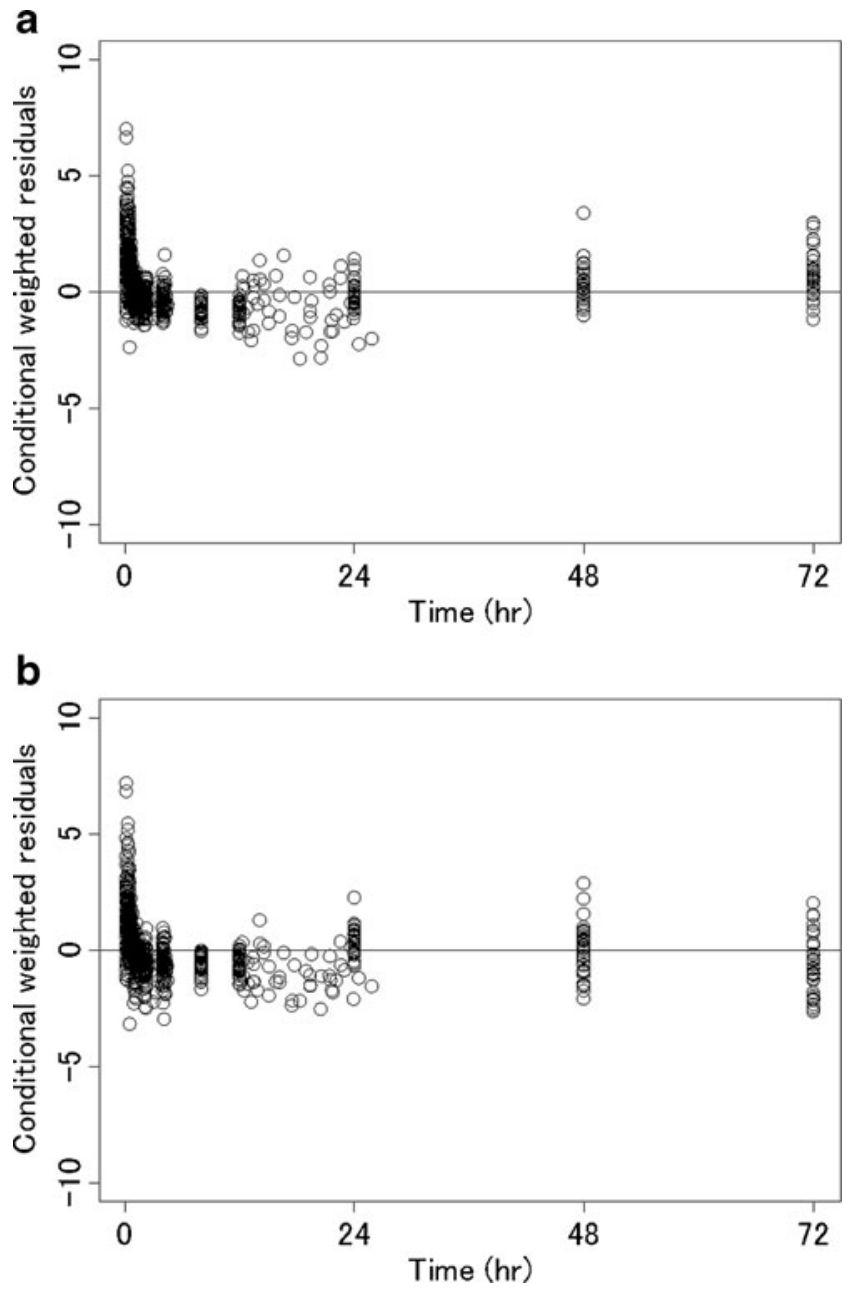

Fig. 6 Time versus the individual conditional weighted residuals plots using our data. a Odani's population pharmacokinetic model. b Ahn's population pharmacokinetic model phase. Therefore, the one-compartment model was inappropriate for studying the pharmacokinetics of phenytoin after intravenous fosphenytoin sodium injection. All pharmacokinetic parameters correlated with body weight in the present final model and in Odani's model and Ahn's model. The Vd of the present final model was calculated from $\mathrm{V}_{2}$ and $\mathrm{V}_{3}$. The $\mathrm{CL}$ was about 1.4 times higher and the $\mathrm{Vd}$ was about 1.5 times higher at all body weights in Odani's model. It was difficult to compare our final model against Odani's model, because the structural model between these two models was different. However, with respect to $\mathrm{Vd}$, the informative plasma samples that were collected immediately after injection were higher in the present study. Therefore, the estimated $\mathrm{Vd}$ in this study was considered more plausible. The Vd estimates obtained using the final model and Ahn's model were nearly the same, but the CL of Ahn's model was about 0.6 times lower at all body weights. This was because Ahn's model was built on the basis of steady-state data and the data of elderly subjects.

The estimated half-life of conversion from fosphenytoin to phenytoin calculated from $\mathrm{K}_{12}$, which was approximately $8 \mathrm{~min}$, was consistent with the half-life proposed by Boucher et al. [9].

In this study, we used total phenytoin concentration. Therefore, the ramification that fosphenytoin displaces phenytoin from albumin had limited effects.

We used a limited number of patients taking medications, which may have affected the pharmacokinetics. Therefore, we could not examine the influence of concomitant medications.

Many studies have reported that genetic polymorphisms in the drug metabolizing enzymes CYP2C9 and 2C19 can greatly affect the pharmacokinetic parameters of phenytoin in Japanese populations [11-13]. However, genetic information was not collected in this study. Further, collection of this information during routine clinical practice would be difficult. Therefore, we did not examine the influence of genetic polymorphisms in this analysis.

The therapeutic range for phenytoin is considered to be $10-20 \mu \mathrm{g} / \mathrm{mL}$ as the total plasma phenytoin concentrations in patients with normal plasma protein binding [10]. Therefore, we used this index for the simulations.

The results of the simulations showed that the total plasma phenytoin concentrations in adult patients were higher than those in pediatric patients. However, administration of $22.5 \mathrm{mg} / \mathrm{kg}$ of fosphenytoin sodium at an infusion rate of $3 \mathrm{mg} / \mathrm{kg} / \mathrm{min}$ was considered to lead to an appropriate profile of total plasma phenytoin concentration in the two groups.

In this study, plasma samples were collected from subjects after single-dose administration. Therefore, we performed only single-dose simulation and proposed a singledose regimen. Further, administration of a maintenance dose is more effective in clinical practice.

Our proposed dose regimen was higher than the approved dose cited in the package insert for phenytoin injection in 
Japan. However, differences in formulation will have more clinical implications. Therefore, differences in the dose regimen would have almost no impact.

\section{Conclusion}

A linear two-compartment model was effective for population pharmacokinetic analysis of phenytoin after intravenous administration of fosphenytoin sodium because no bias was observed in the goodness-of-fit plots obtained using the final model. Therefore, we established the optimal dosage of fosphenytoin sodium injection on the basis of this model. The model and optimal dosage in clinical practice require verification.

\section{Acknowledgements Not applicable.}

Disclosure of conflict of interest The authors declare that they have no conflict of interest. This study was sponsored by Nobelpharma Co., Ltd. (Tokyo, Japan).

Open Access This article is distributed under the terms of the Creative Commons Attribution License which permits any use, distribution, and reproduction in any medium, provided the original author(s) and the source are credited.

\section{References}

1. Odani A, Hashimoto Y, Takayanagi K, Otsuki Y, Koue T, Takano M, Yasuhara M, Hattori H, Furusho K, Inui K (1996) Population pharmacokinetics of phenytoin in Japanese patients with epilepsy: analysis with a dose-dependent clearance model. Biol Pharm Bull 19(3):444-448
2. Yukawa E, Higuchi S, Aoyama T (1990) Population pharmacokinetics of phenytoin from routine clinical data in Japan: an update. Chem Pharm Bull 38(7):1973-1976

3. Frame B, Beal SL (1998) Non-steady state population kinetics of intravenous phenytoin. Ther Drug Monit 20(4):408-416

4. Ahn JE, Cloyd JC, Brundage RC, Marino SE, Conway JM, Ramsay RE, White JR, Musib LC, Rarick JO, Birnbaum AK, Leppik IE (2008) Phenytoin half-life and clearance during maintenance therapy in adults and elderly patients with epilepsy. Neurology 71(1):38-43

5. Beal SL, Sheiner LB (1992) NONMEM users guides. NONMEM Project Group, UCSF, San Francisco

6. Hooker AC, Staatz CE, Karlsson MO (2007) Conditional Weighted Residuals (CWRES): a model diagnostic for the FOCE method. Pharm Res 24(12):2187-2197

7. R Development Core Team (2005) R: a language and environment for statistical computing. R Foundation for Statistical Computing, Vienna, Austria. ISBN 3-900051-07-0, URL http://www.R-project.org. Accessed 1 January 2011

8. Ette EI (1997) Stability and performance of a population pharmacokinetic model. J Clin Pharmacol 37(6):486-495

9. Boucher BA, Bombassaro AM, Rasmussen SN, Watridge CB, Achari R, Turlapaty P (1989) Phenytoin prodrug 3phosphoryloxymethyl phenytoin (ACC-9653): pharmacokinetics in patients following intravenous and intramuscular administration. J Pharm Sci 78(11):929-932

10. Burton ME (2006) Applied pharmacokinetics and pharmacodynamics. Lippincott Williams \& Wilkins, Philadelphia

11. Odani A, Hashimoto Y, Otsuki Y, Uwai Y, Hattori H, Furusho K, Inui K (1997) Genetic polymorphism of the CYP2C subfamily and its effect on the pharmacokinetics of phenytoin in Japanese patients with epilepsy. Clin Pharmacol Ther 62(3):287-292

12. Mamiya K, Ieiri I, Shimamoto J, Yukawa E, Imai J, Ninomiya H, Yamada H, Otsubo K, Higuchi S, Tashiro N (1998) The effects of genetic polymorphisms of CYP2C9 and CYP2C19 on phenytoin metabolism in Japanese adult patients with epilepsy: studies in stereoselective hydroxylation and population pharmacokinetics. Epilepsia 39(12):1317-1323

13. Yukawa E, Mamiya K (2006) Effect of CYP2C19 genetic polymorphism on pharmacokinetics of phenytoin and phenobarbital in Japanese epileptic patients using non-linear mixed effects model approach. J Clin Pharm Ther 31(3):275-282 